\title{
Numerical modelling and rock support design in Codelco's New Mine Level panel caving project
}

\author{
J.A. Jarufe Codelco, Chile, and The University of Western Australia, Australia \\ P. Vasquez Codelco, Chile
}

\begin{abstract}
The New Mine Level Project is a 130,000 tonnes per day (tpd) panel caving project set to start in 2017. The high stresses, complex structural setting and high mining rates presents a major challenge in terms of seismicity management and rockburst hazard reduction. This paper is a case study of the calculation of the energy requirements needed to design a dynamic support system. This analysis starts with the estimation of the seismic source forecasted through the use of numerical modelling and verified with observed past data, later peak particle velocity (ppv) is calculated at the drifts with a ppv attenuation model, and an amplification factor is used near the excavations. Finally, the amount of fractured rock around the drifts that could be ejected by a seismic event is calculated through numerical modelling. With the ejection velocity estimated from ppvs, energy demand can be obtained.
\end{abstract}

All the values resulting from numerical analysis were compared to historical data of similar mine sectors. The results shown that the methodology used in this paper agrees well with previously observed rockburst episodes, therefore it was used to calculate the yielding support of this new deep mine project.

\section{Introduction, The New Mine Level Project and the use of yielding support}

The New Mine Level Project is a 130,000 tpd panel caving project that will be the deeper continuation of the current El Teniente operations. This new project is planned to start production in 2017. Previously, seismic activity and rockburst events have happened at El Teniente (Araneda and Sougarret, 2007; Rojas et al., 2000). New sectors are going to be located 250 to $300 \mathrm{~m}$ deeper, with increasing stresses where fault slip events are to be expected (Potvin and Wesseloo, 2008; Jarufe, 2010; Potvin et al., 2010). The management of the seismic response of the rock mass and the use of containing measures is required to increase the safety of the mining process.

To contain the ejected rock caused by a seismic events (rockburst), the use of yielding support has been implemented successfully in several mines around the world (Varden et al., 2008; Charette, 2012). The implementation of this support technology will be used to reduce the rockburst hazard that could exist in the mine, but a methodology to define the correct support element must be defined. In this paper, the methodology defined by the Canadian Rockburst Support Handbook (Kaiser et al., 1996) is used to calculate the energy demand on the different mining levels of this new project.

\section{$2 \quad$ Yielding support calculation methodology}

The method used to calculate yielding support is based on the steps proposed in the Canadian Rockburst Research Project (Kaiser et al., 1996):

1. Estimation of the most likely location and the maximum magnitude of future events.

2. Estimate ground motion decay from the source to each of the drifts.

3. Estimate the amplification factor in the broken rock mass surrounding the drifts. 
4. Estimation of the yielded rock mass around the drifts, which could be affected by the ground motion.

5. Considering the ppvs and the yielded rock mass (loose zone), the energy demand can be calculated for each level.

Even though there is no definitive way to quantify all the aforementioned steps and much uncertainty exists in the measurements and forecasts, an effort has been made to use the best tools to provide an input value for the design of the support system.

\subsection{Location and magnitude of future large events}

The energy that the support system will need to absorb depends on the magnitude of the expected events and the distance between the drift and the seismic event. This means that a reasonable estimation of the location and magnitude of the event is needed for the analysis. Given that past seismicity and large events have been related to a shear mechanism on faults and contact zones (Potvin et al., 2010, Ground Control internal reports), a Map3D fault slip model was used to calculate the zones of high non-linear displacement that can be related to large fault slip seismic events (Jarufe, 2008; Potvin et al., 2010) (Figure 1). Experience from Map3D modelling has shown that the periods with higher seismicity and the location of the zones where the largest events occur can be correlated with non-linear displacement in Map3D DD fault planes (Jarufe and Vasquez, 2008; Potvin et al., 2010; Jarufe, 2010; Jarufe and Bacco., 2011; Jarufe et al., 2012).

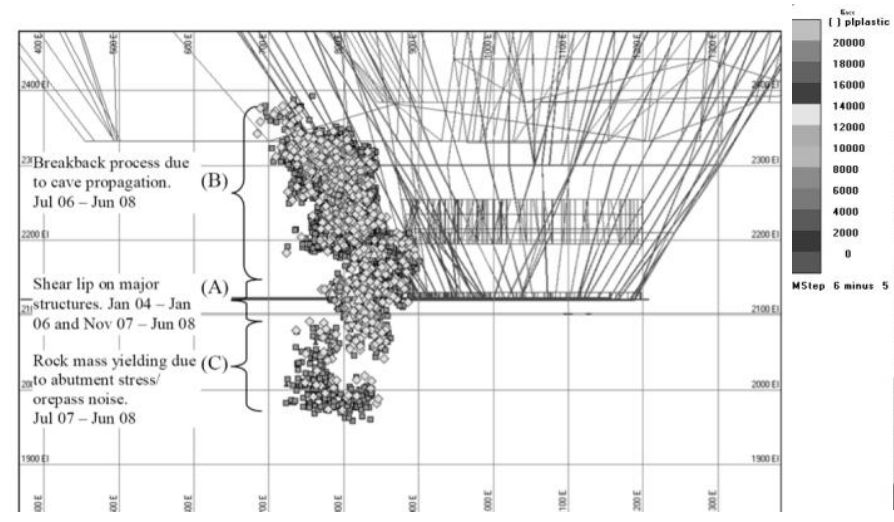

(a)

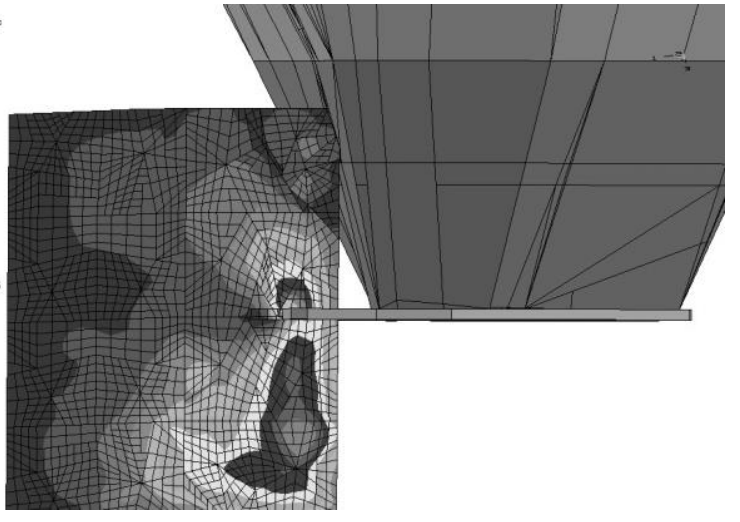

(b)

Figure 1 (a) interpretation of observed seismic data (Potvin and Wesseloo, 2008); (b) results from numerical modelling for the same time period

Using this method, it has been possible to estimate that largest events would likely occur $80 \mathrm{~m}$ below the undercut level (UCL), and that the expected maximum magnitude will be close to Moment magnitude $\mathrm{Mw}=3$ (Figure 2). Given that there are several fault planes and contact zones (which have been seismically active due to past mining), and that modelling results are similar in the location of maximum non-linear displacement for all fault planes (approximately $80 \mathrm{~m}$ below undercut level for all fault planes), the full horizontal plane $80 \mathrm{~m}$ below the undercut level is considered as a seismic source. Those results have been confirmed by other analysis. 


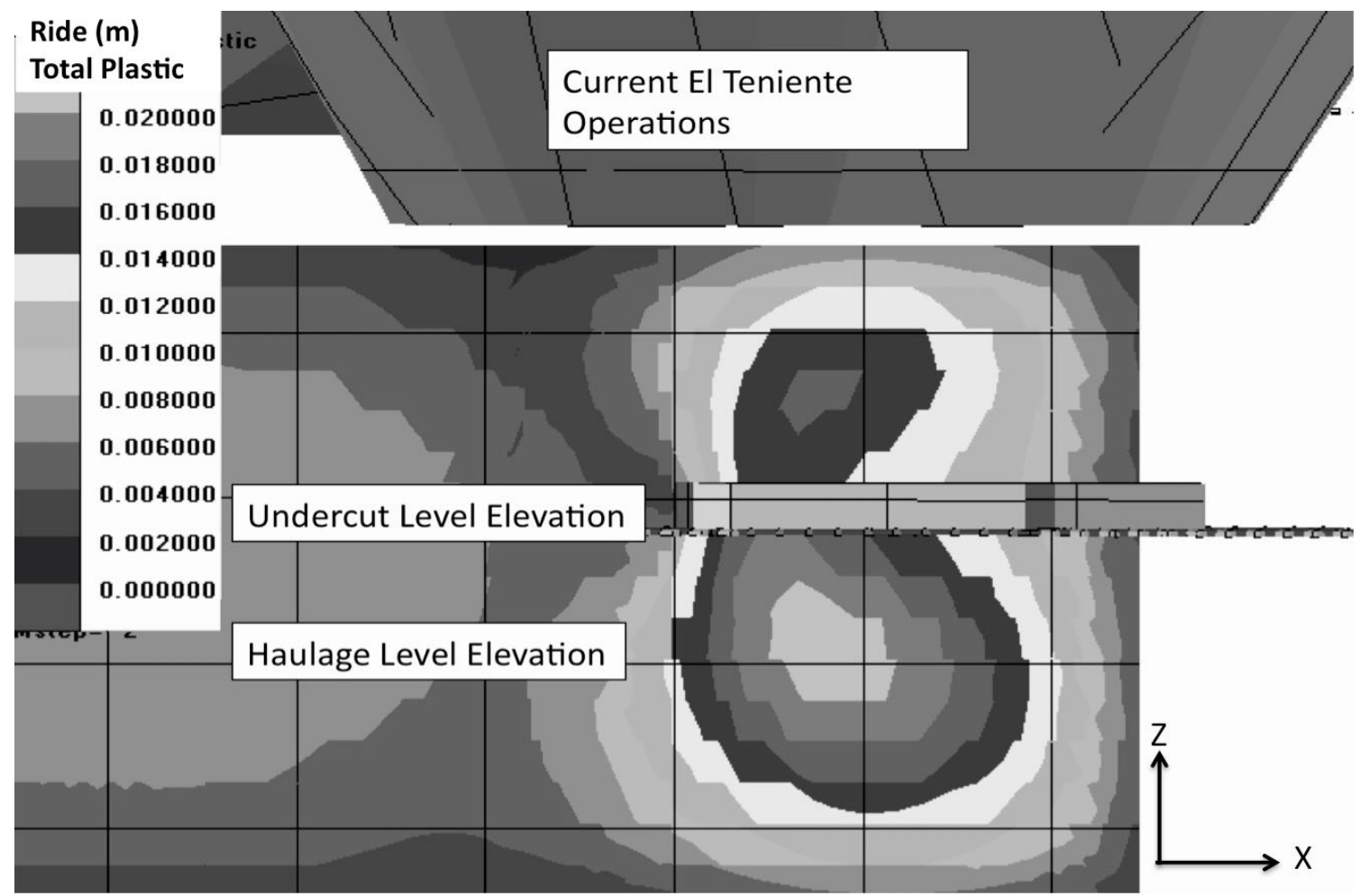

Figure 2 New Mine Level modelling results for a specific fault zone, showing higher displacement values $80 \mathrm{~m}$ below the UCL (grid size is of $100 \mathrm{~m}$ )

\section{2 ppv decay through the rock mass}

Once the locations and magnitudes of events are defined, the energy from the hypothetical event must travel through the rock mass to the different mine sublevels in the mine. To simulate this process, the peak particle velocity (ppv) was calculated at the different drift locations through an attenuation function. To calculate this attenuation of ppvs, measured ppv values, at different locations in the mine (and at different distances from the source) and for different magnitude events, where used to create a chart (Figure 3) that relates the magnitude of the event, the distance and the ppv to create a ppv decay model.

Similar attenuation models can be found in literature (Kaiser et al., 1996) but in this analysis, a model based on the local database was used. Comparison of the local model with the literature proposed models shows a good correlation at distances higher than $100 \mathrm{~m}$. However, at closer ranges, there are few observations and the measured data seems to be not as high as that estimated in the Canadian Rockburst Research Project (Figure 4). In the rest of the analysis, a model based on the local data will be used. 


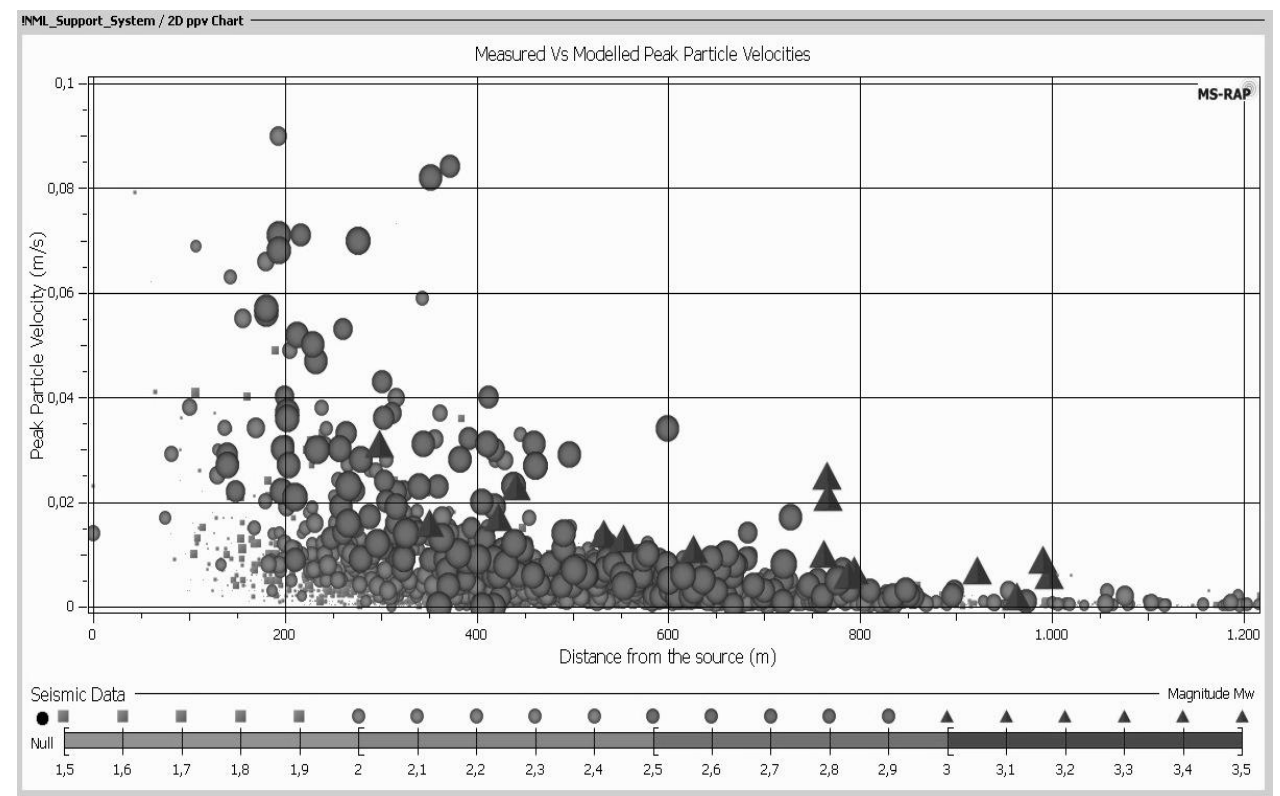

(a)

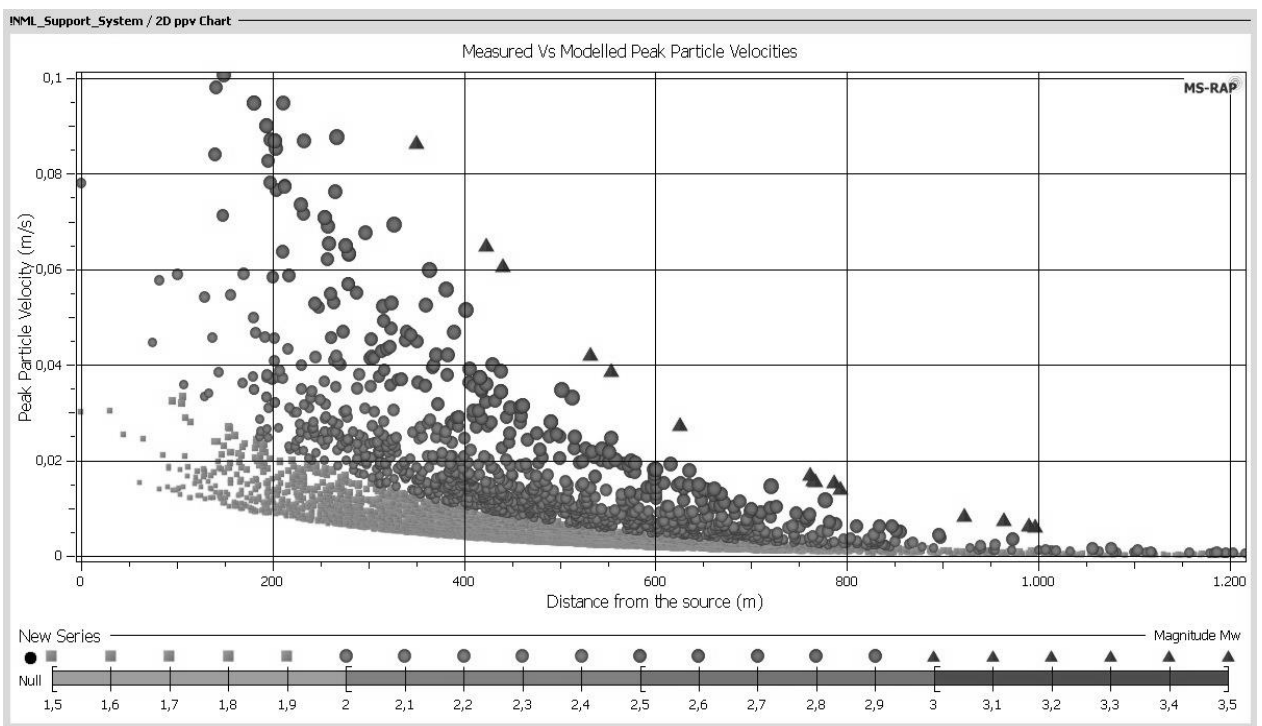

(b)

Figure 3 (a) measured ppvs for different distances; (b) ppv model used for this analysis. It can be seen that there is few data recorded for distances below $100 \mathrm{~m}$ 


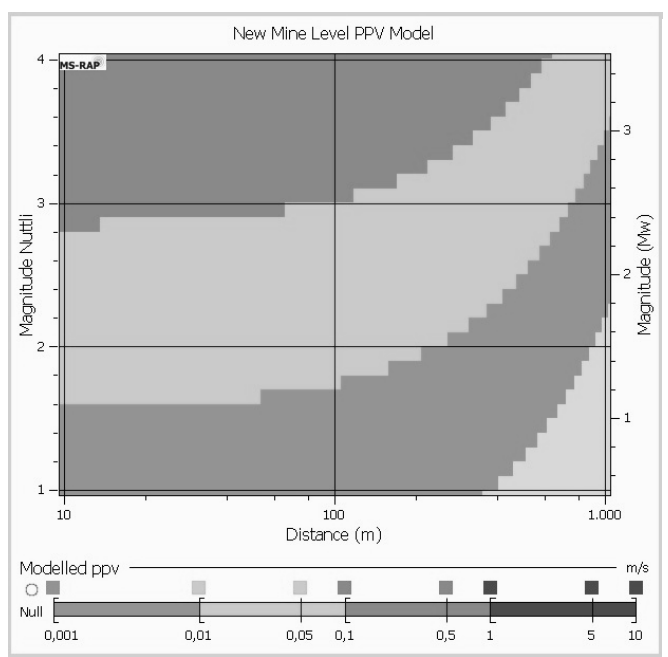

(a)

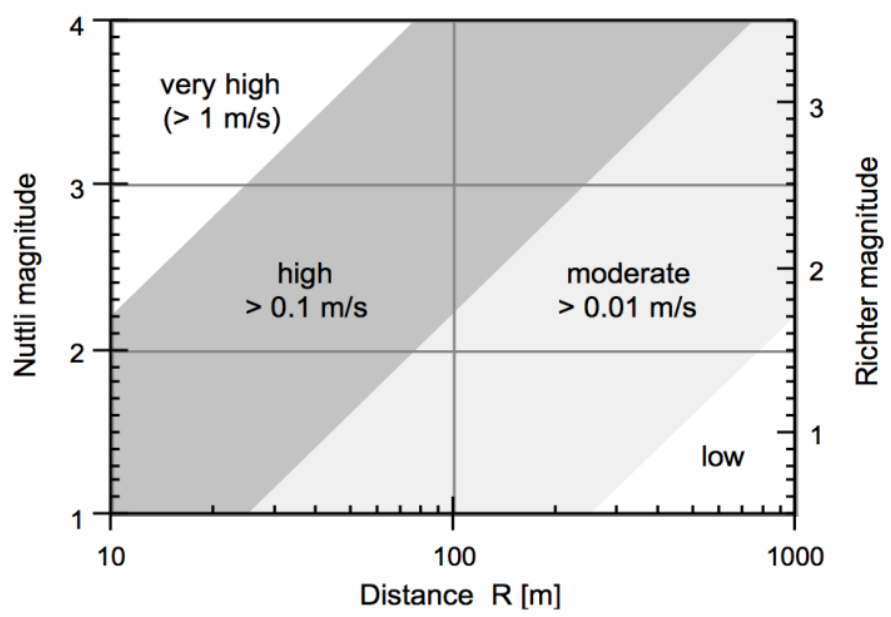

(b)

Figure $4 \mathrm{ppv}$ values from the attenuation model for elastic medium of the New Mine Level (a) compared to Canadian Rockburst Research Project (b) (Kaiser et al., 1996). It can be seen the effect of having few data below $100 \mathrm{~m}$

Using the proposed attenuation model, different velocities are obtained for the various sublevels of the New Mine Level Project (Table 1).

Table 1 Expected ppvs at different New Mine Level sublevels due to the largest expected event $(M w=3)$

\begin{tabular}{ccccc}
\hline Sublevel & Elevation $(\mathrm{m})$ & $\begin{array}{c}\text { Distance to Seismic } \\
\text { Hypocentre }(\mathbf{m})\end{array}$ & \multicolumn{2}{c}{ ppv $(\mathrm{m} / \mathrm{s})$} \\
& & 80 & 0.07 & 0.39 \\
\hline Average & Max \\
Extraction & 1,862 & 62 & 0.08 & 0.42 \\
Ventilation-2 & 1,844 & 44 & 0.08 & 0.45 \\
Ventilation-3 & 1,826 & 26 & 0.08 & 0.48 \\
Haulage & 1,808 & 8 & 0.09 & 0.51 \\
Drainage & 1,790 & 10 & 0.09 & 0.51 \\
\hline
\end{tabular}

\section{3 ppv amplification at contours of drifts}

Several authors have stated that the ppv is amplified close to the boundaries of underground excavations. This amplification has been shown to be dependent on the magnitude of the events and, more specifically, to the corner frequency of the event (Figure 5) (Alviña, 2008; Van Sint Jan, 2008).

For the current analysis, a two-dimensional analysis of wave propagation was used (Alviña, 2008). This 2D finite element analysis considers a wave propagating through elastic material where different drift shapes, seismic event frequencies and degraded zone around drifts were evaluated. 


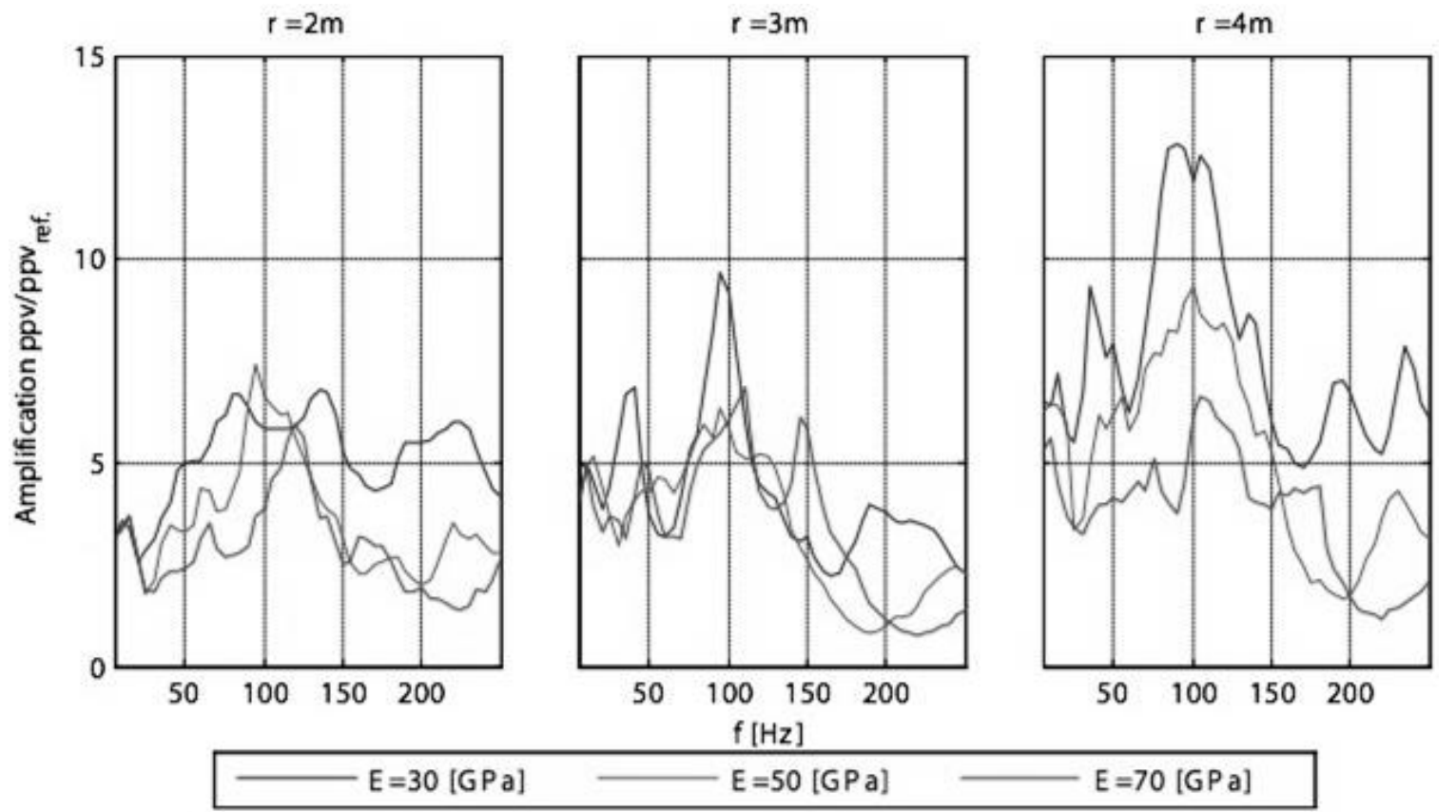

Figure 5 Maximum ppv amplification for a circular drift as a function of the drift radius and the corner frequency of the event (Van Sint Jan, 2008)

Considering the previous analysis and applying it to New Mine Level project conditions, an amplification factor of 12 was chosen. This amplification was imposed at the ppvs calculated previously with the decay function, resulting in the values shown in Table 2.

Table 2 Expected ppvs at different New Mine Level sublevels drift walls due to the largest expected event $(\mathrm{Mw}=3)$

\begin{tabular}{ccccc}
\hline Sublevel & Elevation $(\mathrm{m})$ & $\begin{array}{c}\text { Distance to Seismic } \\
\text { Hypocentre }(\mathbf{m})\end{array}$ & \multicolumn{2}{c}{ Amplified ppv $(\mathrm{m} / \mathrm{s})$} \\
& & 80 & 0.85 & 4.07 \\
\hline Undercut & 1,880 & 62 & 0.92 & 5.05 \\
Extraction & 1,862 & 44 & 0.97 & 5.35 \\
Ventilation-2 & 1,844 & 26 & 1.04 & 5.80 \\
Ventilation-3 & 1,826 & 8 & 1.09 & 6.15 \\
Haulage & 1,808 & 10 & 1.09 & 6.15 \\
Drainage & 1,790 & & & Max \\
\hline
\end{tabular}

When the selected amplification value is compared with previous research in this field, it can be noted that the chosen value of 12 is near the median of the values reported by Milev et al., 2002 (Figure 6). 
Tau Tona: all data

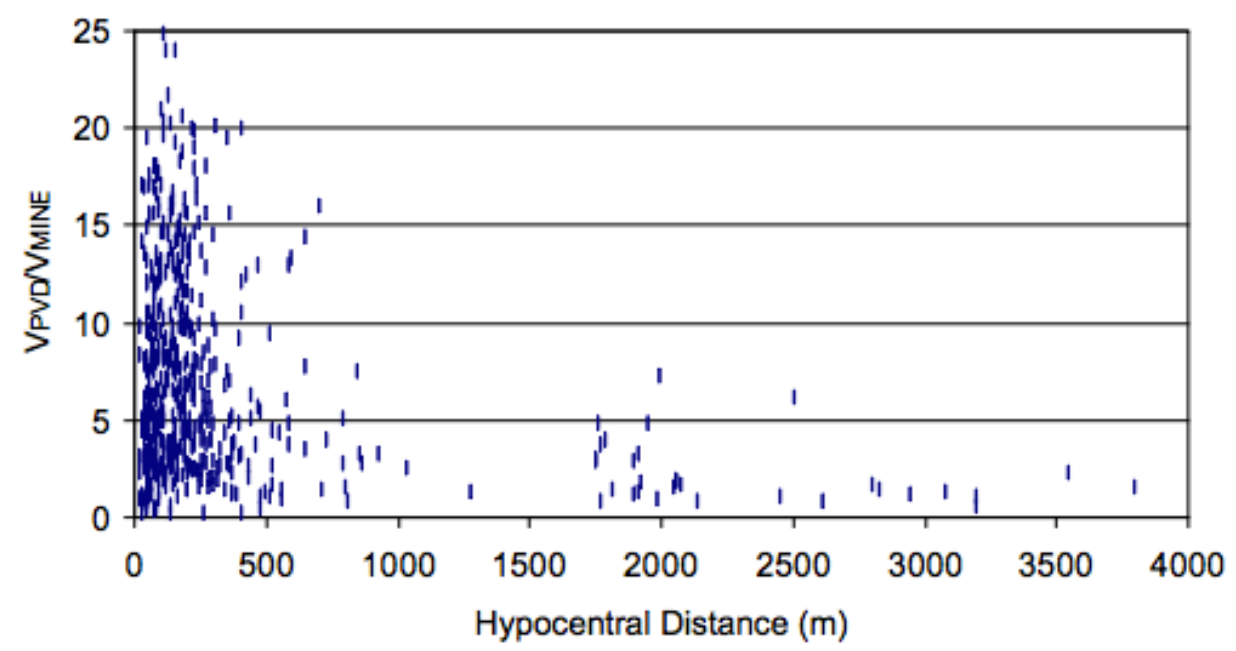

Figure 6 Ratio between ppvs measured by the mine seismic system (Vmine), and the ppvs measured at the surface of the drifts (Vpvd) at Tau Tona Mine (Milev et al., 2002)

\subsection{Loose rock around drifts that could be ejected}

Once the particle velocity is estimated, the calculation of the rock mass that could be ejected is needed to estimate the amount of total energy required to be contained. The calculation of the amount of yielded or loose rock around the drifts could be done through the use of numerical modelling calibrated with ground observations. The most common mechanisms that cause rock instabilities around drifts are high stress yielding and structurally controlled failures. Numerical modelling packages such as Map3D and Unwedge, were used in this analysis to estimate stress induced and structurally controlled failures respectively.

Map3D has been widely used in El Teniente and several other mines to estimate the amount of stress damage around drifts (Jarufe and Vasquez, 2008). Also, the use of Unwedge (Rocscience) has been extensively used to define large blocks that could jeopardise operations on the different levels where structural wedges could form. The simulation of existing drifts, and the comparison between the modelled results and the real observed data has shown good results in the past, with a perceptual difference between measured and modelled over-break of $10 \%$ in terms of extent of loose rock.

With calibrated models it has been possible to estimate the amount of over-break of the different sublevels (Jarufe and Bacco, 2011). Figure 7 shows tons of loose rock around the drifts at each sublevel, measured in the left vertical axis as the metres below the undercut level where the sublevel is located. The undercut and production levels suffer the highest levels of stress-induced damage, with observed loose zone thickness up to $2.5 \mathrm{~m}$. This is because these two levels are strongly affected by mine-induced stresses. As we move away from the undercut levels (more than $50 \mathrm{~m}$ below undercut level in Figure 7), the level of damage starts to decrease as the result of the increasing distance to the productive area (undercutproduction levels).

When the mining face is closest to the drifts, the highest stress damaged levels are those that are closest to the undercut level, with an estimated thickness of loose zone up to $2.5 \mathrm{~m}$. As the drift moves away from the mass mining sectors (undercut level), the amount of damage around the drifts starts to decrease. 


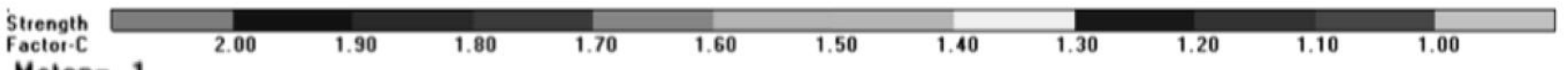

Factor-C

.90

1.80

1.70

$\sigma s=118 \mathrm{~m}=5.870 \mathrm{~s}=0.188 \mathrm{Std}=10.0$
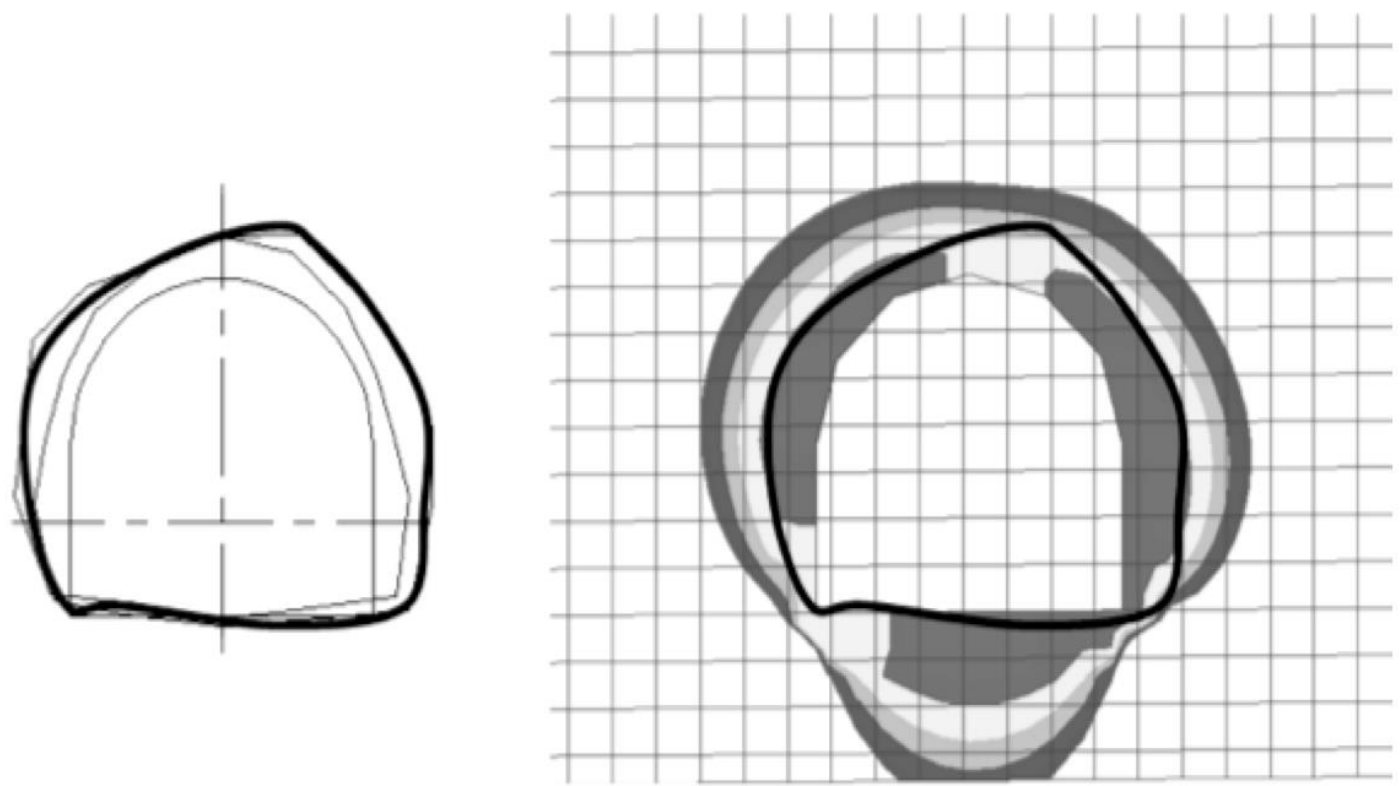

(a)

Loose rock around drifts calculated from numerical modelling

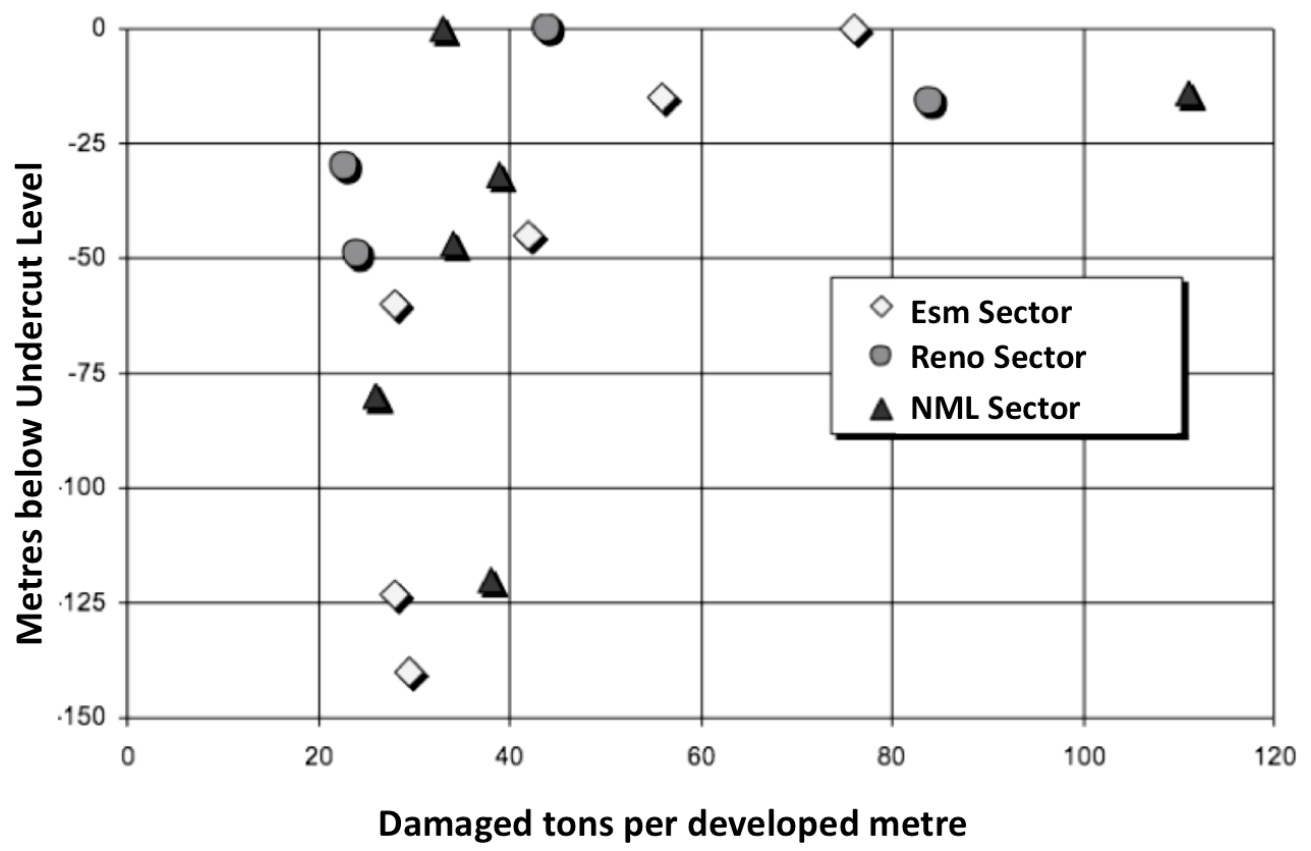

(b)

Figure 7 (a) Example of Map3D comparison between modelled result and observed overbreak for different mine sectors and different sublevels; (b) overbreak values estimated for different sublevels (Jarufe and Bacco, 2011)

It is important to note that in this stage of the project only access drifts are under development, intersections have not been evaluated yet. In these points, higher loose rock values are to be expected and will need special support considerations. 


\subsection{Calculation of energy demand}

Once the velocity of the ppv and the mass of the loose rock zone have been calculated, the energy demand at each drift can be calculated. This is done using the relation:

$$
E=1 / 2 m v^{2}
$$

Where:

$\mathrm{E} \quad=\quad$ energy $(\mathrm{KJ})$.

$\mathrm{m}=\quad$ the loose zone mass (Ton).

$\mathrm{v}=\quad=$ ejection velocity calculated from the amplified $\mathrm{ppvs}(\mathrm{m} / \mathrm{s})$.

From this relation the energy demand can be calculated for the different levels, where the mass is calculated as the loose zone per metre of drift advance and divided by perimeter (thus, the energy is expressed in terms of $\mathrm{m}^{2}$ ) the results from this calculation are shown in Table 3.

Table 3 Expected energy demand for the different levels at the New Mine Level Project

\begin{tabular}{|c|c|c|c|c|c|c|}
\hline \multirow[t]{2}{*}{ Sublevel } & \multirow{2}{*}{$\begin{array}{c}\text { Distance to } \\
\text { Seismic } \\
\text { Hypocentre (m) }\end{array}$} & \multicolumn{2}{|c|}{ Amplified ppv (m/s) } & \multirow{2}{*}{$\begin{array}{c}\text { Fractured } \\
\text { Zone Around } \\
\text { Drifts }\left(\mathrm{T} / \mathrm{m}^{2}\right)\end{array}$} & \multicolumn{2}{|c|}{ Energy Demand $\left(\mathrm{KJ} / \mathrm{m}^{2}\right)$} \\
\hline & & Average & Max & & Average & Max \\
\hline Undercut & 80 & 0.85 & 4.07 & 3.3 & 1.21 & 36.30 \\
\hline Extraction & 62 & 0.92 & 5.05 & 12.2 & 5.13 & 114.84 \\
\hline Ventilation-2 & 44 & 0.97 & 5.35 & 2.5 & 1.17 & 35.89 \\
\hline Ventilation-3 & 26 & 1.04 & 5.80 & 2.5 & 1.34 & 42.02 \\
\hline Haulage & 8 & 1.09 & 6.15 & 2.5 & 1.49 & 47.28 \\
\hline Drainage & 10 & 1.09 & 6.15 & 2.5 & 1.49 & 47.28 \\
\hline
\end{tabular}

\section{Comparison with past rockburst events}

For past rockburst events, it is possible to estimate the amount of energy needed to cause the observed rock ejection (Kaiser et al., 1996). The analysis of 10 years of rockburst data has shown that most of the energy demand is below $80 \mathrm{KJ} / \mathrm{m}^{2}$ (Figure 8). The higher values of energy may correspond to intersections of drifts that were not analysed in this analysis. When the results of this analysis are compared to the historic values (Figure 8) it can be seen that the results obtained are in agree with more than $90 \%$ of the rockburst that have caused damage in the past. This comparison with past data has been considered to validate the results obtained in this work. 


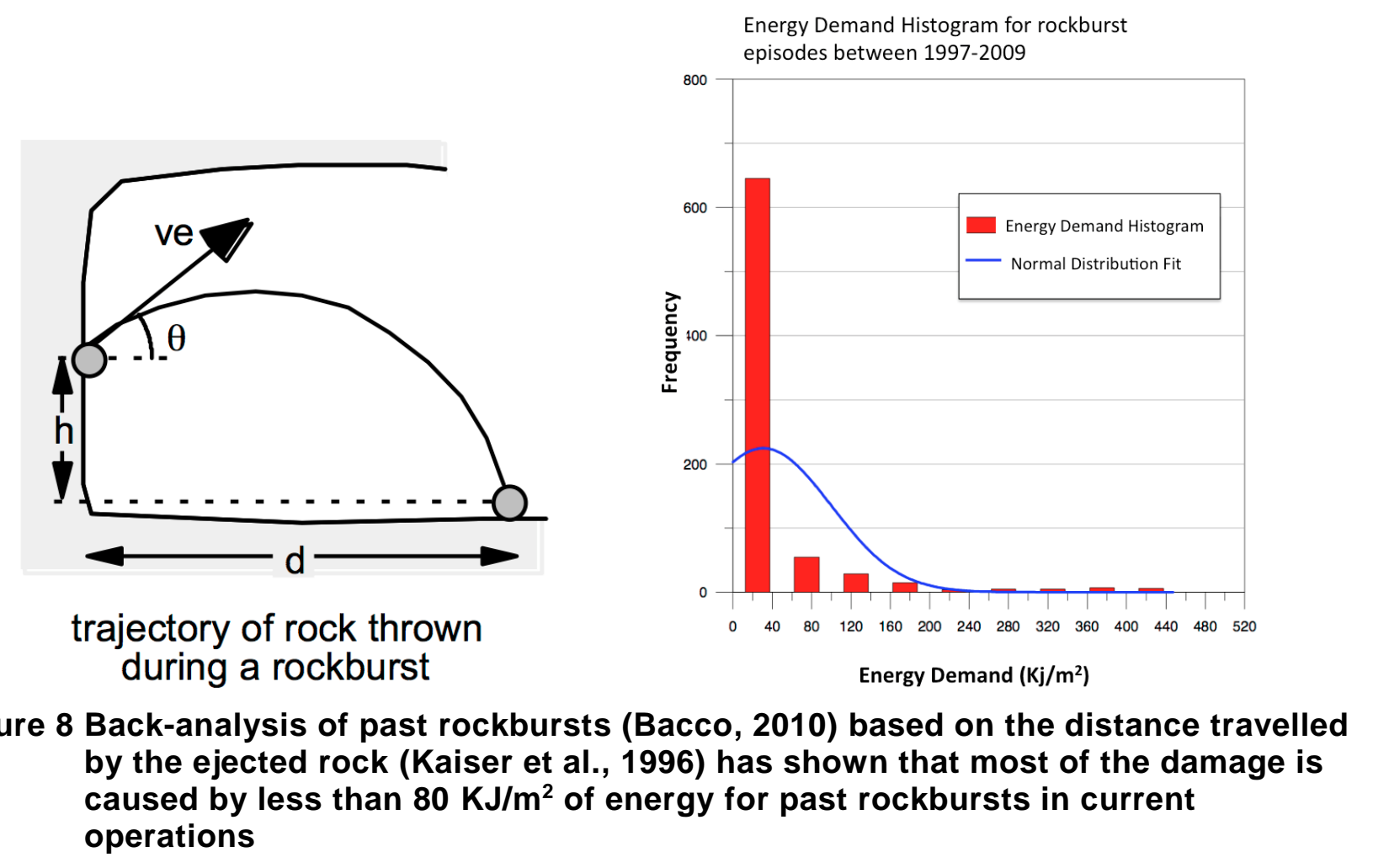

\section{Conclusions}

The calculation of the energy transmitted from a seismic event to the drifts in a mine layout has been a difficult task. A lot of work has been undertaken and is still ongoing; nevertheless, we are still far away from a definitive answer. This presents a major problem for the engineers wanting to design a support system as the energy to be contained needs to be identified in order to select the appropriate support elements. In this work it has been shown that by using the current accepted concepts, it is possible to get quantitative values for the calculation of the support elements. The comparison of the results of this work with previous data can give a measure of reliability of the results. In the analysed example, the results are considered reliable enough to design and implement a yielding support system.

\section{Acknowledgement}

The author thanks the New Mine Level Project management for the support of this work.

\section{References}

Alviña, N. (2008) Analisis Numerico del comportamiento dinamico de tuneles ante eventos sismicos, caso del estallidos de roca en El Teniente, Tesis para optar al grado de Magister en Ciencias de la Ingenieria, Escuela de Ingenieria, Universidad Catolica.

Araneda, O. and Sougarret, A. (2007) Keynote Address: Lessons Learned in Cave Mining, El Teniente 1997-2007, Cave Mining, The South African Institute of Mining and Metallurgy, Cape Town, pp. 59-71.

Bacco, M. (2010) Post Evaluacion Sistemas de Fortificacion Division El Teniente, New Mine Level Project Internal Report.

Charette, F. (2012) Applicability of D-Bolt in High Stress Conditions, Health \& Safety Ontario, viewed 20 March 2013, http://www.healthandsafetyontario.ca/HSO/media/WSN/Resources/WSN-2012-F-Charette-Applicability-of-D-Bolt-in-HighStress-Conditions.pdf.

Jarufe, J. (2010) Actividad Sismica Asociada a Fallas Maestras en Sector Reservas Norte y su Aplicacion al Proyecto Nuevo Nivel Mina, New Mine Level Project, Internal Report, № T09E205-F1-VCPNNM-20000-INFGE04-2000-017-P.

Jarufe, J. (2008) Preentacion avances riesgo sismico Proyecto Nuevo Nivel Mina, Internal Report, New Mine Level Project.

Jarufe, J. and Bacco, M. (2011) Analisis Geomecanico De Disposicion De Niveles Para El Proyecto Nuevo Nivel Mina, New Mine Level Project, Internal Report, № T09E205-F1-VPNNM-00000-INFGE04-0000-002-P.

Jarufe, J. and Vasquez, P. (2008) Mine-Scale 3D Stress Model for the New Mine Level Project, El Teniente Mine, Codelco, Chile, in Proceedings First Southern Hemisphere International Rock Mechanics Symposium (SHIRMS), Y. Potvin, J. Carter, A. Dyskin and R. Jeffrey (eds), Vol. 1 - Mining and Civil, 16-19 September 2008, Perth, Australia, Australian Centre for Geomechanics, Perth, pp. 231-242. 
Jarufe, J., Potvin, Y. and Wesseloo, J. (2012) Application of the limit equilibrium strength to the seismic assessment of shear related seismicity, in Proceedings Sixth International Seminar on Deep and High Stress Mining (Deep Mining 2012), Y. Potvin (ed), 28-30 March 2012, Perth, Australia, Australian Centre for Geomechanics, Perth, pp. 389-400.

Kaiser, P.K., McCreath, D.R. and Tannant, D.D. (1996) Canadian Rockburst Support Handbook, Mirarco, Sudbury, Canada.

Milev, A.M., Spottiswoode, S.M., Noble, B.R., Linzer, L.M., van Zyl, M., Daehnke, A. and Acheampong, R. (2002) The meaningful use of peak particle velocities at excavations surfaces for the optimization of the rockburst criteria for tunnels and stopes. RASIM GAP-709, Final Project Report.

Potvin, Y. and Wesseloo, J. (2008) Findings from Seismic Data Analysis at Reno, New Mine Level Project, Internal Report.

Potvin, Y., Jarufe, J. and Wesseloo, J. (2010) Interpretation of seismic data and numerical modelling of fault reactivation at El Teniente, Reservas Norte sector, Mining Technology, Vol. 119, No. 3, 2010, pp. 175-181(7).

Rojas, E., Cavieres, P., Dunlop, R. and Gaete, S. (2000) Control of Induced Seismicity at El Teniente Mine Codelco-Chile, in Proceedings MassMin 2000, G. Chitombo (ed), 29 October - 2 November 2000, Brisbane, Australia, Australasian Institute of Mining Metallurgy, Melbourne.

Van Sint Jan, M. and Alviña, N. (2008) Ground movement amplification around underground excavations, Newsletter Australian Centre for Geomechanics, Australian Centre for Geomechanics, Perth, Australia, Vol. 31, December 2008, pp. 21-22.

Varden, R., Lachenicht, R., Player, J., Thompson, A. and Villaescusa, E. (2008) Development and Implementation of the Garford Dynamic Bolt at the Kanowna Belle Mine, in Proceedings Tenth Underground Operators Conference, 14-16 April 2008, Launceston, Australia, Australasian Institute of Mining and Metallurgy, Carlton. 
Numerical modelling and rock support design in Codelco`s New Mine Level panel J.A. Jarufe and P. Vasquez caving project 